\title{
PERFORMANCE OF BURSA-WOLF MODEL FOR DEFORMING REGION: CASE STUDY IN MALAYSIA
}

\author{
Noraziera Azahar ${ }^{1}$, Wan Anom Wan Aris ${ }^{1}$, Tajul Ariffin Musa ${ }^{1}$, Abdullah Hisam Omar ${ }^{1}$, Ivin Amri Musliman ${ }^{1}$ \\ ${ }^{1}$ Faculty of Built Environment and Surveying, Universiti Teknologi Malaysia
}

Commission 4, WG 7

KEY WORDS: Bursa-Wolf, Coordinate Transformation, Coordinate Residual.

\begin{abstract}
Bursa-Wolf model is a common mathematical approach for coordinate transformation practice between two reference frames. For the case of deforming region, the existing reference frame has been experiencing a non-linear shifting over the time due to coseismic and post seismic occurrences. Imprecise coordinate in the reference frame definition could degrading critical positioning, surveying, and navigation activities. This require a new realization of reference frame and the coordinate transformation linkage is suggested to be developed in relating the new and existing reference frame. This study provides performance of Bursa-Wolf model as coordinate transformation approach for a deforming region that is experiencing non-linear shifting due to the co-seismic and postseismic events. TLhe Bursa-Wolf were generated from 32 dependent Global Positioning System (GPS) Continuously Operating Reference Stations (CORS) in Malaysia meanwhile another 20 independent neighbouring stations were utilized for assessment purposes. Seven parameters $(7 \mathrm{p})$ of Bursa-Wolf were estimated with RMS at $\pm 4.5 \mathrm{~mm}, \pm 9.2 \mathrm{~mm}$ and $\pm 2.1 \mathrm{~mm}$ respectively. The independent stations were classified as internal and external assessment station and the root mean square (RMS) were found at less than $10 \mathrm{~mm}$. The internal station has depicted a better RMS in each component which are $\pm 5.1 \mathrm{~mm}, \pm 6.5 \mathrm{~mm}$ and $\pm 1.5 \mathrm{~mm}$ respectively. Meanwhile for external stations RMS in each component are $\pm 6.1 \mathrm{~mm}, \pm 8.7 \mathrm{~mm}$ and $\pm 3.5 \mathrm{~mm}$ respectively. The result shows that Bursa-Wolf model is sufficient to be used as coordinate transformation approach for deforming region.
\end{abstract}

\section{INTRODUCTION}

Cartesian coordinate transformations in three-dimensional (3D) space are commonly used in surveying, photogrammetry and geodesy (Păun et al., 2017; Zeng et al; 2020). They are also called similarity of mathematical relationships between points in two different 3D coordinate systems (Tao et al., 2020). The process involved similarity parameter estimation consists of translation, rotation and scale (Gao et al., 2017; Amiri et al., 2018).

Deforming regions such as Indonesia, New Zealand, and Malaysia, are facing a significant coordinate shifting over the time due to continuous tectonic displacement (Blick et al., 2010; Shariff et al., 2017; Syetiawan et al., 2019). The series of great earthquakes since 2004 have significantly affected the Sundaland plate velocity field (Yong et al., 2017). Hill et al (2015) also found that the $M w$ 8.6 Wharton Basin event caused many different faults ruptured as the static displacement of this event were up to $22 \mathrm{~cm}$. This situation causes datum alignment between national and global reference frame thus degrading its compatibility with satellite-based positioning. A new realization of reference frame is necessary, and the coordinate transformation linkage is suggested to be developed to relate the new and existing reference frame for surveying and mapping purposes (Banko et al., 2020).

Malaysia is situated outside the Sunda ring of fire (Mustafar et al., 2017). The region comprises of two (2) mainlands; Peninsular Malaysia and Northern Borneo, both are being affected by major earthquakes in Western belt of Sunda (Tongkul, 2017; Nazaruddin et al., 2021). Aris et al (2016) found that a continuous post-seismic deformation at $39 \mathrm{~cm} / \mathrm{year}$ in Peninsular Malaysia due to 2004 Sumatra Andaman (9.2Mw), 2005 Nias Simeulue (8.5Mw), 2007 Bengkulu
(7.9Mw) and 2012 Indian Ocean (8.6Mw). Due to this circumstance, a new realization of reference frame in Malaysia with semi-kinematic datum approach was suggested by considering the secular and non-secular deformation (Azhari et al, 2020). Failing to account for this effect can introduce velocity error up to $0.5 \mathrm{~mm} / \mathrm{yr}$ (Tregoning et al., 2013). Thus, performance of coordinate transformation is necessary to be understood in relating the new and existing reference frame.

Bursa-wolf model is one of practical mathematical approach for coordinate transformation and have been used widely for geodetic reference frame in deforming regions (Syetiawan et al., 2019; Abbey et al., 2020). One important characteristic feature of this model is that the shape of the geodetic network containing the coordinates to be transformed is preserved, hence angles are not altered after transformation, but the coordinate difference between the transformed coordinates and their original positions could be changed (Ziggah et al., 2019). This coordinate difference needs to be understood in order to investigate the performance of Bursa-Wolf model.

This study provides performance of Bursa-Wolf model as coordinate transformation approach for a deforming region. The experimental work utilised geodetic network in Malaysia, a region that is experiencing non-linear shifting due to the coseismic and post-seismic events (Azhari et al, 2020; Aris et al., 2016). The first reference frame is Geodetic Datum of Malaysia 2000 (GDM2000) which is the standard geodetic datum for the country (Azhari et al, 2020). Meanwhile, the second reference frame is based on self-realization in International Terrestrial Reference Frame 2014 (ITRF2014@2018.0) at similar geodetic framework. It is worth to mention that the results and analysis is mainly for experimental purposes only. 
This paper is divided in four (4) sections. Section 2 describes the methodology, mathematical concept as well as assessment approach. Result and analyses are discussed in Section 3. Finally, concluding remarks is drawn in Section 4.

\section{METHODOLOGY}

Figure 1 shows general flow-chart of the work that comprises of three (3) process which are; coordinate transformation parameter estimations based on Bursa-wolf model, coordinate transformation application, and finally assessment of the coordinate difference. The following sub-sections explain each process in detail.

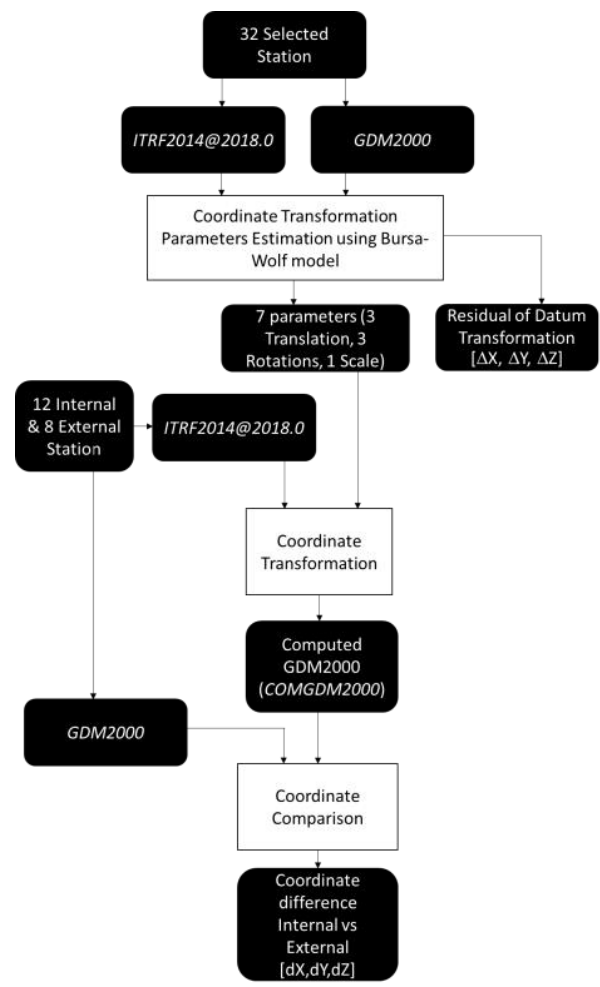

Figure 1. General flow-chart of methodology.

\subsection{DISTRIBUTION OF THE GEODETIC NETWORK}

This transformation process utilised set of coordinates (GDM2000 and ITRF2014@2018.0) from geodetic network of GPS CORS Malaysia Real-Time Kinematic network (MyRTKnet). Thirty-two (32) of them as shown in Figure 2 were treated as dependent stations. These stations were used for the $7 p$ estimations thus creating a network of Bursa-Wolf model. Meanwhile, another twenty (20) GPS CORS as shown in Figure 3 were treated as independent station for coordinate residual calculation during assessment stage. Noted that these twelve (12) and eight (8) independent stations were situated within internal and external network of the Bursa-Wolf model, respectively.

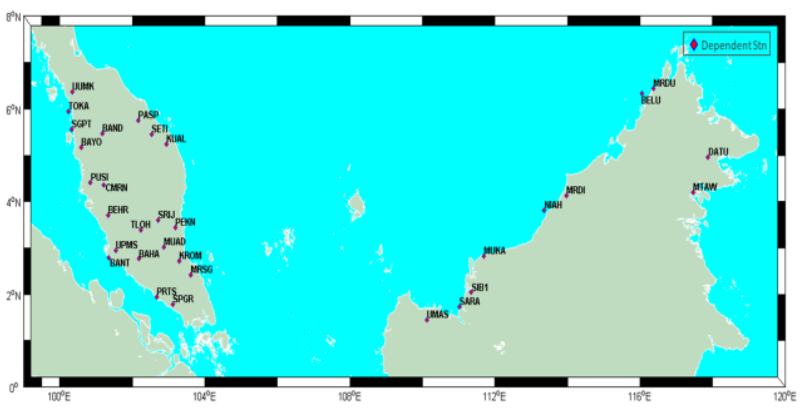

Figure 2. Dependent Stations.

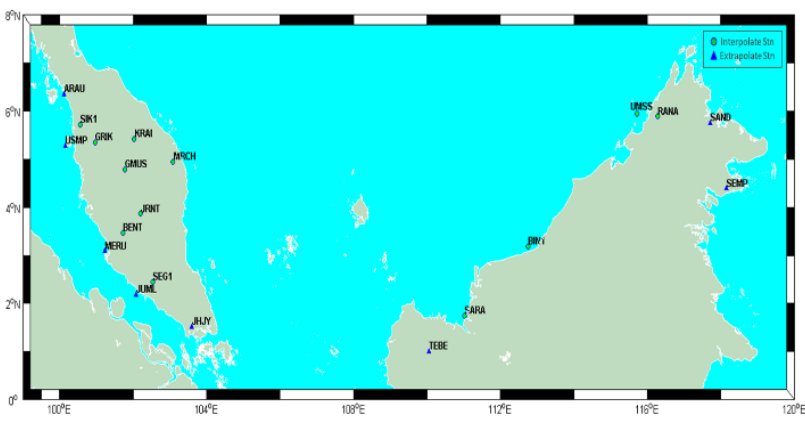

Figure 3. Independent Station.

\subsection{COORDINATE TRANSFORMATION PARAMETER ESTIMATIONS BASED ON BURSA-WOLF MODEL}

The Bursa-Wolf model provides a mathematical formula for transformation between two reference frames in 3D Cartesian coordinate system by using $7 \mathrm{p}$. The $7 \mathrm{p}$ comprise of three datum translations on $\mathrm{X}$-axis, $\mathrm{Y}$-axis and $\mathrm{Z}$-axis $(t \mathrm{X}, \mathrm{tY}, \mathrm{tZ})$, three rotations $\left(R_{X}, R_{Y}, R_{Z}\right)$, and one scale factor $(1+\Delta s)$. Equation (1) shows the Bursa-Wolf model with the $7 \mathrm{p}$ as given by Deikan (2006);

$\left[\begin{array}{c}X_{G D M 2000} \\ Y_{G D M 2000} \\ Z_{G D M 2000}\end{array}\right]=\left[\begin{array}{c}t X \\ t Y \\ t Z\end{array}\right]+\left[\begin{array}{ccc}1+\Delta s & R_{Z} & -R_{Y} \\ -R_{Z} & 1+\Delta s & R_{X} \\ R_{Y} & -R_{X} & 1+\Delta s\end{array}\right]\left[\begin{array}{c}X_{I T R F 2014} \\ Y_{I T R F 2014} \\ Z_{I T R F 2014}\end{array}\right]$

Where $X_{G D M 2000}, Y_{G D M 2000}, Z_{G D m 2000}$ is the Cartesian coordinates in GDM2000 and $X_{\text {ITRF 2014 }}, Y_{\text {ITRF2014 }}, Z_{\text {ITRF2014 }}$ is the Cartesian coordinates in ITRF2014@2018.0. The 7p in Equation (1) can be estimated by using the inverse transformation approach as in Equation (2).

$$
\left[\begin{array}{c}
X_{G D M 2000} \\
Y_{G D M 2000} \\
Z_{G D M 2000}
\end{array}\right]=+\frac{R^{-1}}{(1+S)}\left[\left[\begin{array}{c}
X_{I T R F 2014} \\
Y_{I T R F 2014} \\
Z_{I T R F 2014}
\end{array}\right]-\left[\begin{array}{c}
t X \\
t Y \\
t Z
\end{array}\right]\right]
$$

The accuracy, $S$ of estimated 7p Bursa-Wolf model in term of Root-Mean-Square-error (RMS), can be computed as shown on Equation (3) and (4).

$S=\left(A^{T} P A\right)^{-1} \cdot \hat{\sigma}$
$\hat{\sigma}=\sum\left(V^{T} P V\right) / r$

Where $\left(A^{T} P A\right)^{-1}$ is designed matrix from Equation [1], $V$ is coordinate residual at dependent stations, $P$ is weighted matrix and $r$ is number of dependent stations. 


\subsection{COORDINATE TRANSFORMATION INDEPENDENT STATION}

AT

Coordinate transformation by using the Bursa-Wolf $7 \mathrm{p}$ will be applied at both internal and external independent stations. The equation can be expressed as follow;

$$
\begin{aligned}
{\left[\begin{array}{l}
X_{\text {COMGDM2000 }} \\
Y_{\text {COMGDM2000 }} \\
Z_{\text {COMGDM2000 }}
\end{array}\right]=} & {\left[\begin{array}{c}
t X \\
t Y \\
t Z
\end{array}\right]+} \\
& {\left[\begin{array}{ccc}
1+\Delta s & R_{z} & -R_{Y} \\
-R_{Z} & 1+\Delta s & R_{X} \\
R_{Y} & -R_{X} & 1+\Delta s
\end{array}\right]\left[\begin{array}{l}
X_{G D M 2000} \\
Y_{G D M 2000} \\
Z_{G D M 2000}
\end{array}\right] }
\end{aligned}
$$

Where $X_{\text {COMGDM2000 }}, Y_{\text {COMGDM } 2000}, Z_{\text {COMGDM } 2000}$ is the Cartesian coordinate of computed GDM2000 after applying $7 \mathrm{p}$ and $X_{G D M 2000}, Y_{G D M 2000}, Z_{G D M 2000}$ is the Cartesian coordinates in GDM2000

\subsection{COORDINATE DIFFERENCE COMPUTATION}

For the validation of the parameter estimation, the two cases by internal and external station were used to be compared with the original coordinate and giving the equation as below:

$$
\begin{aligned}
d X, d Y, d Z= & {\left[X_{G D M 2000}, Y_{G D M 2000}, Z_{G D M 2000}\right]-} \\
& {\left[X_{\text {COMGDM2000 }}, Y_{\text {COMGDM 2000 }}, Z_{\text {COMGDM2000 }}\right] }
\end{aligned}
$$

Where $X_{\text {COMGDM2000 }}, Y_{\text {COMGDM2000 }}, Z_{\text {COMGDM2000 }}$ is the Cartesian coordinate of computed GDM2000 after applying $7 \mathrm{p}$ and $X_{G D M 2000}, Y_{G D M 2000}, Z_{G D M 2000}$ is the Cartesian coordinates in GDM2000

\section{RESULT AND ANALYSIS}

This section provides results and analysis; accuracy of BursaWolf $7 p$ estimation, and assessment of Bursa-wolf model in coordinate transformation application.

\subsection{Accuracy of Bursa-Wolf 7p estimation}

Figure 4 shows residual in Bursa-Wolf $7 p$ estimations in 3D Cartesian coordinate $\mathrm{X}, \mathrm{Y}$ and $\mathrm{Z}$ components illustrated in Figure 4 . The RMS value for every components are $\pm 4.5 \mathrm{~mm}$, $\pm 9.2 \mathrm{~mm}$ and $\pm 2.1 \mathrm{~mm}$ respectively. Small amount of RMS indicates acceptable $7 \mathrm{p}$ Bursa-Wolf parameter estimation. Further work was conducted to the see the residual pattern in spatial sense. Thus, the residuals were then converted into horizontal vector as shown in Figures 5. From the figures, uneven direction of residual in horizontal vectors is depicted for all location which varies between $-4.5 \mathrm{~mm}$ and $4.0 \mathrm{~mm}$. Large horizontal vector can be seen at northern and southern part of Peninsular Malaysia, and gradually decreasing towards the centre of the region. This could be explained by a driven seismic motion due to on-going post-seismic deformation. Significant horizontal vector also found in the south-eastern of Borneo which can be explained by a slow and continuous local deformation within the area.

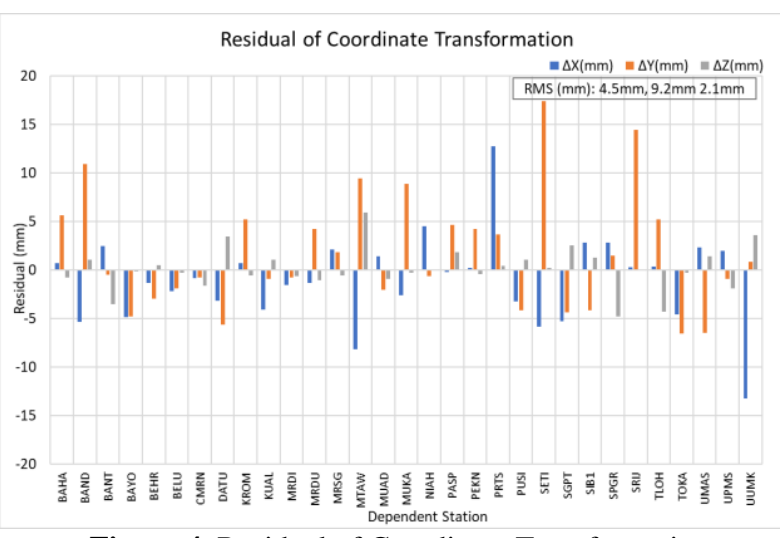

Figure 4. Residual of Coordinate Transformation.

HORIZONTAL RESIDUAL OF DATUM TRANSFORMATION

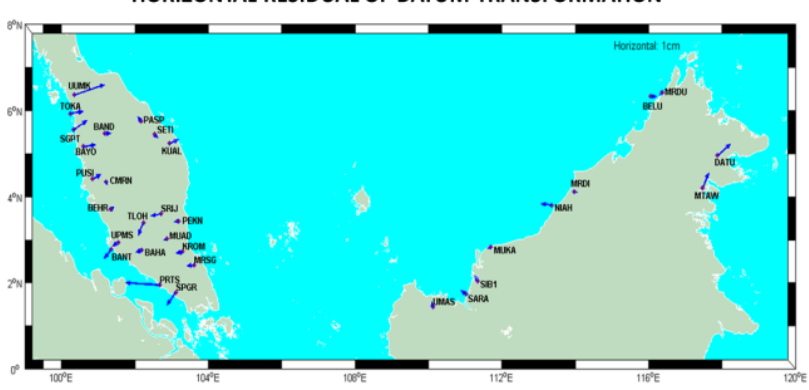

Figure 5. Horizontal residual of Bursa-Wolf in Malaysia.

\subsection{Assessment of Coordinate Transformation based on the 7p Bursa-Wolf model}

The assessment results from coordinate transformation based on the 7p Bursa-Wolf model is illustrated in Figure 6 and 7. Both figures provide variation of coordinate difference in $3 \mathrm{D}$ Cartesian components, $\mathrm{X}, \mathrm{Y}$ and $\mathrm{Z}$ at Independent Station; internal and external, respectively. From the figures, the RMS of coordinate difference at internal station can be achieved at $\pm 5.1 \mathrm{~mm}, \pm 6.5 \mathrm{~mm}$ and $\pm 1.5 \mathrm{~mm}$ for the three components, respectively. The result shows slightly better than RMS of coordinate transformation at external station which are at $\pm 6.1 \mathrm{~mm}, \pm 8.7 \mathrm{~mm}$ and $\pm 3.3 \mathrm{~mm}$ respectively.

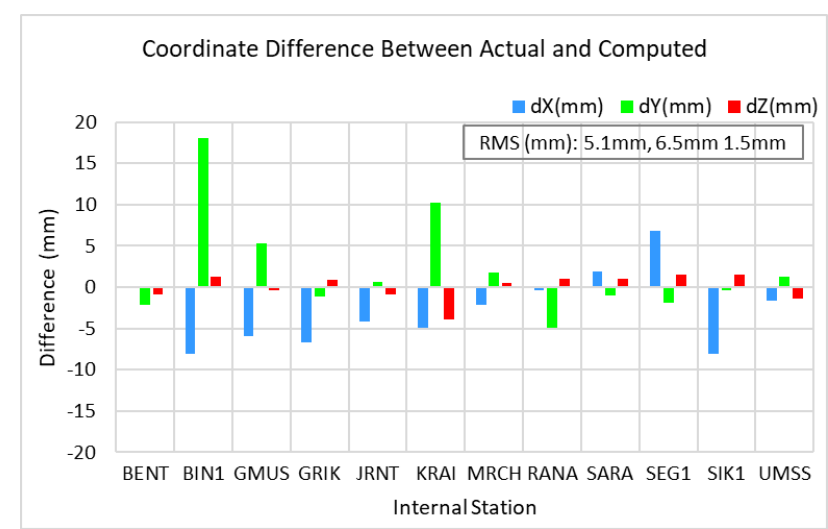

Figure 6. Coordinate difference at Independent Station (internal) after applying the 7p Bursa-Wolf model. 


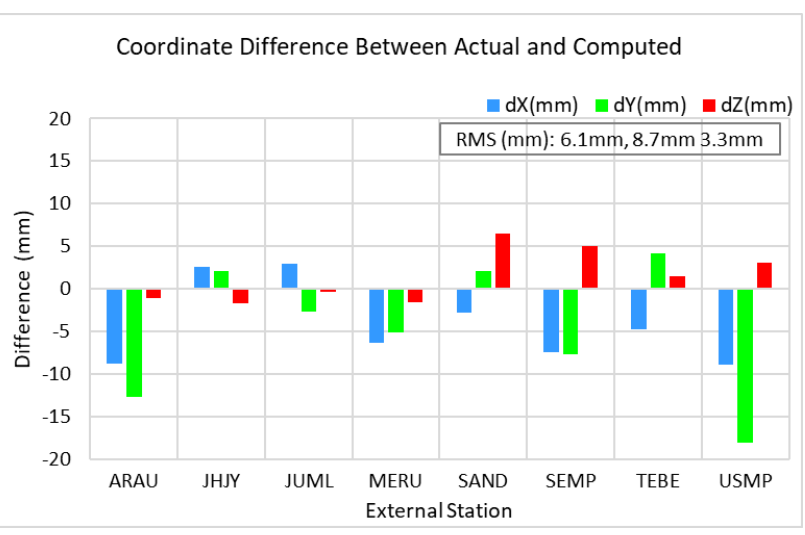

Figure 7. Coordinate difference at Independent Station (external) after applying the 7p Bursa-Wolf model.

Based on Figure 6, internal station BIN1 depicts largest coordinate difference at $-8.1 \mathrm{~mm}, 18.1 \mathrm{~mm}$ and $1.3 \mathrm{~mm}$ for the northing, easting and up component respectively. This is because the BIN1 has a longest distance at approximately $110 \mathrm{~km}$ to the nearest dependent station of NIAH. Station BENT situated approximately $57 \mathrm{~km}$ from nearest dependent station of TLOH and depicts small coordinate difference at $0.1 \mathrm{~mm}$, $2.1 \mathrm{~mm}$ and $-0.1 \mathrm{~mm}$ for the northing, easting and up component respectively. Unlike external stations, uneven coordinate difference is found and with unclear relationship to their distance to the dependent stations. However, this external station still exhibits acceptable coordinate difference and the $7 p$ Bursa-Wolf models is adequate to be used in this region.

\section{CONCLUSION AND RECOMMENDATION}

This study demonstrated analysis on the performance of BursaWolf model for coordinate transformation approach in deforming region such as Malaysia. The experimental work utilised two reference frames which are GDM2000 and ITRF2014@2018.0 from self-derivation. The accuracy of Bursa-Wolf $7 p$ estimations exhibits acceptable RMS value at $\pm 4.5 \mathrm{~mm}, \pm 9.2 \mathrm{~mm}$ and $\pm 2.1 \mathrm{~mm}$ in $3 \mathrm{D}$ Cartesian coordinates respectively. Large horizontal vector was found in the northern and southern part of Peninsular Malaysia as well as southeastern of Borneo. These can be explained by a slow and continuous post-seismic and local deformation. Comparative analysis of independent stations indicated that internal stations depicted better RMS value as compared to external station. The assessment of the 7p Bursa-Wolf shows RMS of coordinate difference less than $\pm 6.5 \mathrm{~mm}$ at internal station. The external station shows coordinate difference exceeded up to $\pm 8.7 \mathrm{~mm}$. However, this external station still exhibits acceptable coordinate difference and the $7 \mathrm{p}$ Bursa-Wolf models is adequate to be used in this region. It is worth to mention that the results and analysis is mainly for experimental purposes only. Further work is recommended to optimize the Bursa-Wolf model for coordinate transformation in the deforming region by applying coordinate correction from the coordinate difference value.

\section{ACKNOWLEDGEMENTS}

This research is fully supported under Universiti Teknologi Malaysia grant for Malaysia Geodetic Coordinate Utility Program (18J75). The authors fully acknowledged Ministry of Higher Education (MOHE) and University Technology Malaysia for the approved fund which makes this important research viable and effective.

\section{REFERENCES}

Abbey, D. A., \& Featherstone, W. E. (2020). Comparative Review of Molodensky-Badekas and Burša-Wolf Methods for Coordinate Transformation. Journal of Surveying Engineering, 146(3), http://dx.doi.org/10.1061/(ASCE)SU.1943-5428.0000319

Amiri-Simkooei, A. R. (2018). Parameter estimation in 3D affine and similarity transformation: implementation of variance component estimation. Journal of Geodesy, 92(11), 1285-1297. http://dx.doi.org/10.1007/s00190-018-1119-1

Aris, W. A. W., Musa, T. A., \& Omar, K. (2016). Estimation Of Co-And Postseismic Deformation After The Mw 8.6 NiasSemeulue And Mw 8.5 Bengkulu Earthquakes From Continuous Gps Data. The International Archives of Photogrammetry, Remote Sensing and Spatial Information Sciences, 42, 61. http://dx.doi.org/10.5194/isprs-archives-XLII4-W1-61-2016

Azhari, M., Altamimi, Z., Azman, G., Kadir, M., Simons, W. J. F., Sohaime, R., ... \& Saiful, A. (2020). Semi-kinematic geodetic reference frame based on the ITRF2014 for Malaysia. Journal of Geodetic Science, 10(1), 91-109. http://dx.doi.org/10.1515/jogs-2020-0108

Banko, A., Banković, T., Pavasović, M., \& Đapo, A. (2020). An All-in-One Application for Temporal Coordinate Transformation in Geodesy and Geoinformatics. ISPRS International Journal of Geo-Information,9(5), 323. http://dx.doi.org/10.3390/ijgi9050323

Blick, G., \& Grant, D. (2010). The implementation of a semidynamic datum in New Zealand-ten years on. In XXIV FIG Congress (pp. 1-14).

Deakin, R. E. (2006). A note on the Bursa-Wolf and Molodensky-Badekas transformations. School of Mathematical and Geospatial Sciences, RMIT University, 1-21

Gao, Y. (2017). Analysis of coordinate transformation with different polynomial models (Bachelor's thesis). http://dx.doi.org/10.18419/opus-9644

Hill, E. M., Yue, H., Barbot, S., Lay, T., Tapponnier, P., Hermawan, I., ... \& Sieh, K. (2015). The 2012 Mw 8.6 Wharton Basin sequence: A cascade of great earthquakes generated by near-orthogonal, young, oceanic mantle faults. Journal of Geophysical Research: Solid Earth, 120(5), 3723-3747.

Mustafar, M. A., Simons, W. J., Tongkul, F., Satirapod, C., Omar, K. M., \& Visser, P. N. (2017). Quantifying deformation in North Borneo with GPS. Journal of Geodesy, 91(10), 12411259. http://dx.doi.org/10.1007/s00190-017-1024-z

Păun, C. D., Oniga, V. E., \& Dragomir, P. I. (2017). ThreeDimensional Transformation of Coordinate Systems using Nonlinear Analysis-Procrustes Algorithm. Int. J. Eng. Sci. Res. Technol, 6, 355-363. http://dx.doi.org/10.5281/zenodo.291839

Shariff, N. S., Gill, J., Amin, Z. M., \& Omar, K. M. (2017). Towards The Implementation of Semi-Dynamic Datum For Malaysia. International Archives of the Photogrammetry, Remote Sensing \& Spatial Information Sciences, 42. http://dx.doi.org/10.5194/isprs-archives-XLII-4-W5-185-2017 
Syetiawan, A., Ramdani, D., Safii, A. N., Ardhitasari, Y., Gaol, L., \& Annuriah, I. (2019). Development of Parameter Transformation of Indonesian Geospatial Reference System 2013. The 1st International Conference on Geodesy, Geomatics, and Land Administration 2019, KnE Engineering, pages 77--94. http://dx.doi.org/10.18502/keg.v4i3.5828

Tao, W., Hua, X., \& Feng, S. (2020). Performing 3d Similarity Transformation with Large Rotation Angles Using Constrained Multivariate Total Least Squares. Boletim de Ciências Geodésicas, $26 . \quad$ http://dx.doi.org/10.1590/s198221702020000400021

Tongkul, F. (2017). Active tectonics in Sabah—seismicity and active faults.

Tregoning, P., Burgette, R., McClusky, S. C., Lejeune, S., Watson, C. S., \& McQueen, H. (2013). A decade of horizontal deformation from great earthquakes. Journal of Geophysical Research: Solid Earth, 118(5), 2371-2381.

Yong, C. Z., Denys, P. H., \& Pearson, C. F. (2017). Present-day kinematics of the Sundaland plate. Journal of Applied Geodesy, 11(3), 169-177.

Zeng, H., Chang, G., He, H., \& Li, K. (2020). WTLS iterative algorithm of 3D similarity coordinate transformation based on Gibbs vectors. Earth, Planets and Space, 72(1), 1-12. http://dx.doi.org/10.1186/s40623-020-01179-1

Ziggah, Y. Y., Youjian, H., Tierra, A. R., \& Laari, P. B. (2019). Coordinate transformation between global and local data based on artificial neural network with $\mathrm{K}$-fold cross-validation in Ghana. Earth Sciences Research Journal,23(1), 67-77. https://doi.org/10.15446/esrj.v23n1.63860 